\title{
Primum non nocere-it takes a village
}

\author{
Joel D. Cooper, MD
}

From the Hospital of the University of Pennsylvania, University of Pennsylvania Health System, Philadelphia, Pa. Disclosures: Author has nothing to disclose with regard to commercial support.

Received for publication Oct 30, 2017; accepted for publication Nov 9, 2017; available ahead of print Jan 13, 2018.

Address for reprints: Joel D. Cooper, MD, University of Pennsylvania School of Medicine, Hospital of the University of Pennsylvania, Department of Surgery, Division of Thoracic Surgery, 3400 Spruce St 6 White, Philadelphia, PA 19104 (E-mail: Joel.cooper@uphs.upenn.edu).

J Thorac Cardiovasc Surg 2018;155:1910-1

$0022-5223 / \$ 36.00$

Copyright (C) 2017 by The American Association for Thoracic Surgery

https://doi.org/10.1016/j.jtcvs.2017.11.013

The article by Fiorelli and colleagues ${ }^{1}$ in this issue of the Journal is a brief, well-illustrated report of a simplified method for introducing a silicone T-tube through an existing tracheostomy stoma to stent a benign subglottic stricture. Because such strictures are often quite tight and tortuous, withdrawing the upper limb of the T-tube through the stricture can be challenging. The authors propose passing a heavy silk suture through the proximal wall of the T-tube and exerting upward force by means of traction on the silk suture that is passed through the rigid bronchoscope that has been used to dilate the stricture.

Like other previously reported techniques which they reference, their procedure also has its limitations, specifically the risk of tearing the wall of the tube if too much force is exerted on the suture. To prevent this, the authors suggest using a very fine needle for passing the suture through the silicone tube and preliminary dilation of the stricture with a large rigid bronchoscope to ease the upper end of the tube through the narrowed segment. This can be especially problematic when the subglottic stricture is tight and involves, as it usually does, the cricoid ring, the most rigid, nondistensible region of the subglottic airway. I agree with the authors that none of the previously described methods (including those proposed by this writer) are ideal.

The authors report satisfactory results with their technique as a "palliative treatment" in 5 patients with postintubation subglottic stenosis considered "unfit for surgery." Therein lies an important issue.

Unquestionably, a silicone T-tube offers a great advantage over a tracheostomy tube in terms of comfort, morbidity, ease of management, restoration of a normal voice, humidification, and ease of clearing secretions. Furthermore, if stenting of the subglottic airway is deemed the most appropriate treatment for an individual patient, there is essentially no alternative to the silicone T-tube because expandable wire stents may cause significant further damage (as noted by the so-called "black box" warning issued by the Food and Drug Administration more than 10 years ago) and straight silicone stents in this

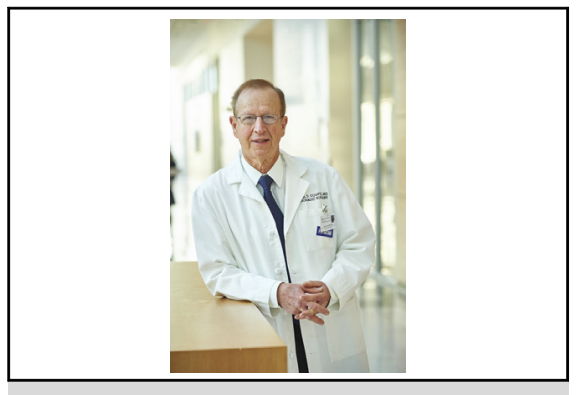

Joel D. Cooper, MD

Central Message

Management of airway problems in the subglottic region, that difficult interface between the trachea and larynx, has benefited greatly over the years from the coordinated efforts of surgeons and physicians.

See Article page 1912.

region are inadvisable because of the potential for mucous plugging and displacement (although techniques for suture fixation in place have been proposed.)

The most common use of a silicone T-tube is not as palliation but to provide a temporary, comfortable, safe upper airway in patients with postintubation subglottic strictures until the patient is in optimum condition to consider surgical resection, which can usually be accomplished with relatively low risk and a very high success rate. This may mean delaying until the patient has fully recovered from the accident or illness that required intubation and ventilation in the first place and concomitant treatment of any comorbidities. In some cases, this may take a year or more and require physical therapy, optimization of weight, treatment of chronic respiratory problems, or additional unrelated surgical procedures. Only then can a decision be made as to whether the patient is truly "unfit for surgery." Because the silicone tubes are fabricated from "implant-grade" silicone, they can be left in place for years with no injury to the underlying mucosa and can be custom-made by the manufacturer (Hood Laboratories, Pembroke, Mass) to the precise length desired, based on bronchoscopic measurements.

Other methods to maintain adequate upper airway patency in the interim, such as repeated use of laser, cryoablation, repeated dilatation, or use of an expandable wire stent, may cause further damage to the subglottic airway, increase the complexity and risk of resection, and reduce the chances for a successful surgical outcome. 
Getting the upper end of a T-tube through a tight and tortuous airway, with its upper end in the very short space between the upper end of the stricture and beneath the vocal cords has not uncommonly taken 2 hours or more using a variety of techniques. In order not to cause any further injury to the immediate subglottic region or to the vocal cords themselves, it may be necessary to have the upper end of the T-tube extend several millimeters above the true vocal cords. Fortunately, the desired length of the upper limb can be provided by the manufacturer based on preliminary endoscopic measurements.
Management of airway problems in the subglottic region, that difficult interface between the trachea and the larynx, has benefited greatly over the years from the coordinated efforts of thoracic and ENT surgeons along with pulmonary physicians, anesthesiologists, and other specialists. With time, patience, and this type of collaborative effort, optimum results can be obtained for the patient.

\section{Reference}

1. Fiorelli A, Carlucci A, Pota V, Santini M. A simplified insertion technique for tracheal T-tube. J Thorac Cardiovasc Surg. 2018;155:1912-4. 